\title{
Comparative study on the libido, semen quality and fertility of Brahman cross, Holstein Friesian cross and Red Chittagong breeding bulls
}

\author{
MM Islam ${ }^{1}$, AS Apu ${ }^{2 *}$, SAM Hoque ${ }^{1}$, MY Ali ${ }^{2}$ and S Karmaker ${ }^{3}$ \\ ${ }^{1}$ Department of Genetics and Animal Breeding, Bangabandhu Sheikh Mujibur Rahman Agricultural University, \\ Gazipur-1706; ${ }^{* 2}$ Department of Animal Breeding and Genetics, Bangladesh Agricultural University, \\ Mymensingh-2202; ${ }^{3}$ Department of Livestock Services, Dhaka, Bangladesh
}

\begin{abstract}
The present study was undertaken to compare the performance of 8 (eight) breeding bulls of three different genetic groups such as Brahman $\times$ local ( 4 bulls), Holstein Friesian $\times$ local ( 2 bulls) and Red Chittagong ( 2 bulls) based on libido, semen quality and fertility. Semen parameters were evaluated from 30 ejaculates from each bull and fertility rate was calculated based on 60-days non-return rate via AI using these semen samples. Genetic group of breeding bulls had significant $(p<0.05)$ effect on libido. Holstein Friesian cross breeding bulls showed significantly $(p<0.05)$ highest libido $(3.77 \pm 0.15)$ followed

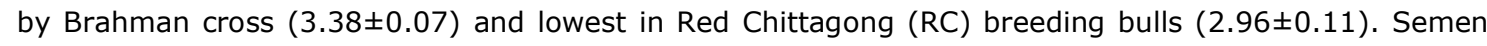
attributes also significantly affected by the different genetic group of bulls. Holstein Friesian crossbred breeding bulls with highest libido provided significantly $(p<0.01)$ highest volume of semen $(5.63 \pm 0.16$ $\mathrm{ml})$ per ejaculate, progressive motility $(74.73 \pm 0.76 \%)$, live sperm $(84.18 \pm 0.62 \%)$ and normal sperm $(83.18 \pm 1.47 \%)$ whereas these parameters were significantly $(p<0.01)$ lowest in RC breeding bulls. Moreover, libido showed a strong and positive correlation with all these semen parameters. The fertility rate was also significantly highest $(p<0.05)$ in Holstein Friesian crossbred breeding bull $(63.67 \pm 1.46 \%)$, followed by Brahman crossbred (58.86 $\pm 1.05 \%)$ and lowest in RC breeding bulls $(53.42 \pm 0.85 \%)$. These results suggested that semen quality is positively correlated with the libido of breeding bulls and quality is important for higher fertility. Therefore, libido as well as semen quality evaluation may be important criteria to discard the breeding bulls with poor fertility in an AI program.
\end{abstract}

Key words: libido, semen quality, sperm morphology, non-return rate

Bangladesh Animal Husbandry Association. All rights reserved.

Bang. J. Anim. Sci. 2018. 47 (2):61-67

\section{Introduction}

Animals showing high libido and appropriate mating capability are the desirable characteristics for a successful breeding program (Chenoweth, 1983; Ahmad et al., 2005). Libido is the desire and excitement of a male animal to mount and do mating with a female animal (Chenoweth, 1981). It is a helpful parameter of measuring reproductive competence (Ahmad et al., 2005) which is calculated by means of the reaction time, defined as the elapsed time between exposure to stimuli and first service (Ott and Memon, 1980). The level of sexual excitement and performance can affect the ejaculatory performance and semen quality (Pound et al., 2002; Levis and Reicks, 2005; Kondracki et al., 2013).

*Corresponding author: auvijit.bau@gmail.com
Bulls with high libido can produce satisfactorily higher number of viable spermatozoa through multiple ejaculates in a relatively short time (Ahmad et al., 2005). Selection of bulls on the basis of sexual behavior and semen quality are more important and economical (Anzar et al., 1993). A bull has a great impact on herd productivity than a single female. So, a bull is aptly said to be "half of the herd". Semen quality of a breeding bull encompasses a package of parameters that represent the inner picture of semen related to fertility which consist volume of semen $(\mathrm{ml})$, mass motility (\%), sperm livability (\%), normal sperm (\%), sperm concentration (million/ml) and nonreturn rate $(\%)$. In our country, the criteria for the selection of bull comprise the milk yield of the dam, phenotypic characteristics, and evaluation of semen characteristics (Ahmad et al., 2003; Khan et al., 2007). The criteria adopted to select a bull of enough reproductive 


\section{Libido, semen quality and fertility of breeding bulls}

ability are seen in latest areas by introducing modern laborious techniques. However, assessment of libido is still a reliable technique to assess the soundness of a bull for selection in breeding program (Mahmood et al., 2014). Testing animals on the basis of libido could provide an easy assessment to select a bull for breeding program. Parkinson (2004) postulated that a bull requires the following criteria to be fertile: physically soundness, good libido, and good quality semen. It is well known that characteristics of semen vary widely between bulls. The differences in semen parameters among bulls may be due to variations in scrotal circumference, breed, age, body size and body weight (Leon et al., 1991 and Sharma et al., 1991). Quality of the semen is affected by both health and nutritional status of the bulls (Soeparna et al., 2013). It is also affected by collection and subsequent handling. In tropical countries, low reproductive performance is a major problem which is associated with semen quality of the stud bull (Annual report of DAPH, 2011).

Andersson et al. (2002) observed a high variability in fertility among bulls using different sperm concentrations per dose at AI. Generally, the non-return rates used as a measure of fertility. In order to evaluate the fertilizing capacity of semen sample a reasonable number of cows is to be inseminated and after 60 days the non-return rate of the cows can be calculated. The non-return rate of bulls depends on holistic semen characteristics of bull, breeding soundness of cows and appropriateness of time and site for semen deposition. The continuous evaluation of semen quality and quantity is required, to achieve higher non return rates.

From the previous review of literatures, it was revealed that no study was conducted to compare the libido, semen quality and fertility rate of our available genetic group of breeding bulls such as Brahman $\times$ Local, Holstein Friesian $x$ Local and RC breeding bulls in Bangladesh. Therefore, the purpose of the present study was to evaluate and compare the libido, semen quality and fertility of these three genetic groups.

\section{Materials and Methods}

\section{Animals and management system}

The present study was conducted at Bangladesh Agricultural University AI Center. Eight (8) bulls of three different genetic groups were used as experimental materials. Experimental bulls were Brahman $\times$ Local bull ID. ABG011, ABG012, ABG013 and ABG014, Holstein Friesian $\times$ Local bull ID 80 and 81 . Brahman cross and Holstein Friesian cross bulls were $50 \%$ crossbred and Red Chittagong Bull ID. 136 and 178 were $100 \%$ purebred. The age of the bulls ranged from 3-5 years. Bulls were maintained under identical feeding and management system throughout the study period.

\section{Measurement of Libido}

Libido of the breeding bull was measured according to Adamczyk et al. (2013) (Table 1).

Table 1: Assessment of bull libido

\begin{tabular}{cl}
\hline Scale & \multicolumn{1}{c}{ Description of behaviour } \\
\hline 0 & $\begin{array}{l}\text { Lack of sex drive. Complete lack of interest. Bull does not sniff or attempt to mount; it } \\
\text { stands next to the teaser animal or attempts to retreat. }\end{array}$ \\
1 & $\begin{array}{l}\text { Very weak sex drive. During } 10 \text {-minute waiting, bull only sniffs the teaser animal with no } \\
\text { attempt to mount. }\end{array}$ \\
2 & $\begin{array}{l}\text { Weak sex drive. Taken to the teaser animal, the bull sniffs it, retreats, sniffs again, makes } \\
\text { a hesitant attempt at mounting, sniffs again, and makes another mount attempt within } 10 \\
\text { minutes. }\end{array}$ \\
3 & $\begin{array}{l}\text { Moderate sex drive. Taken to the teaser animal, the bull sniffs it and begins mount } \\
\text { attempts after } 2-3 \text { minutes. }\end{array}$ \\
4 & $\begin{array}{l}\text { Strong sex drive. Taken to the teaser animal, the bull attempts to mount it at once but } \\
\text { remains calm and is manageable for the handler. }\end{array}$ \\
5 & $\begin{array}{l}\text { Very strong sex drive. Taken to the teaser animal, the bull begins mount attempts at once } \\
\text { and becomes unmanageable for the handler. }\end{array}$ \\
\hline
\end{tabular}




\section{Semen collection and evaluation}

Semen was collected from each bull twice a week by AV (Artificial Vagina) method. A total of 30 ejaculates was collected from each bull and analyzed. Evaluation of fresh semen was performed immediately just after collection using the method described by Herman and Madden (1963). The volume $(\mathrm{ml})$, progressive motility (\%), sperm concentration (million/ml), live sperm count (\%) and normal sperm count (\%) were recorded. Volume was measured directly from the graduated collection vial. Progressive motility was evaluated in a small drop of semen under cover slip with higher magnification. Sperm moving forward were included in the motility count while sperm moving in rotatory or oscillatory motion were excluded (Herman et al., 1994). Sperm concentration was determined by using haemocytometer method. To measure live sperm count, one drop of Eosin-Nigrosin stain was mixed with a small drop of semen on a prewarmed slide. After smearing it was placed on microscope and counted under 40x. On the other hand, after staining with Rose-Bengal Stain, the slide was observed for normal sperm count. All values relating to semen evaluation parameter were expressed as mean \pm standard error (SE).

\section{Fertility}

Fertility of breeding bull was calculated based on the non-return rate of breeding bulls. Fertility was calculated by the number of cows conceived out of the total number of cows inseminated by the semen of respective breeding bulls and inseminated cows not return to estrus within a period of 60 days.

\section{Statistical analyses}

All data were recorded in Excel data sheet and One-way ANOVA test was performed to obtain the difference in volume per ejaculate, mass motility, sperm concentration, live sperm and normal sperm percentage of three genetic groups. Correlation analysis was performed to find the relationship between libido and semen parameters. All statistical analysis were performed by using graph pad prism 5.0 software.

\section{Results and Discussion}

\section{Libido}

The present study was undertaken to evaluate and compare the libido of different breeds and its effect on semen quality and their inter relationships. Libido measurement is a useful tool to judge the reproductive efficiency in a bull. In the current study, we found that breed significantly affected the libido and semen quality of breeding bulls. Holstein Friesian crossbred showed significantly $(p<0.05)$ highest libido $(3.77 \pm 0.15)$ followed by Brahman crossbred bull $(3.38 \pm 0.07)$ and the lowest in RCC Breeding bull (2.96 \pm 0.11$)$ (Figure 1). Similar findings were reported by Rehman et al. (2016). Several other authors also reported varying level of libido in farm animals (Rhen and Crews, 2002; Younis et al., 2003; Ahmad et al., 2005; Kondracki et al., 2013). However, we also found that bulls with higher libido exhibit better semen quality in different breeds. This result also coincides with the findings of Ahmad et al. (2005) who concluded that a bull exhibiting higher libido may carry better semen quality.

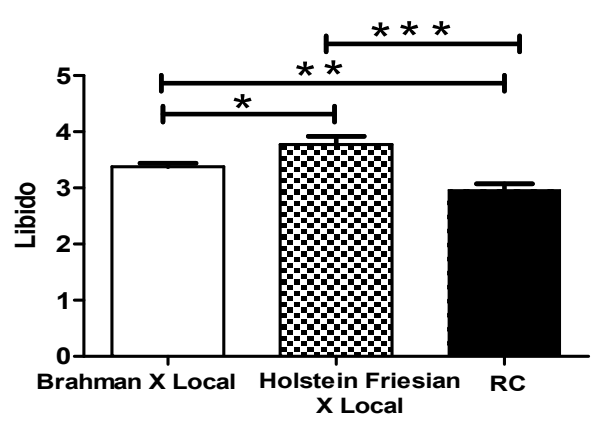

Figure 1: Libido of Brahman cross, Holstein Friesian cross and RC breeding bulls

\section{Semen quality}

\section{Volume}

The volume of the ejaculate significantly $(p<0.01)$ differed among three genetic group of breeding bulls. The highest volume per ejaculate was observed in Holstein Friesian cross bull $(5.63 \pm 0.16 \mathrm{ml})$ and lowest was found in Red Chittagong bull $(3.86 \pm 0.15 \mathrm{ml}$ ) (Table 2). Similar observation was found by Raju and Rao (1982) and Nasrin et al. (2008). Christensen et al. (1999) reported the volume of Holstein Friesian breeding bull was 5.1 with a range of 3.0-8.6. Rashid et al. (2015) and Fatematuzzohora et al. (2016) found $4.00 \pm 0.06$ $\mathrm{ml}$ semen per ejaculate, respectively in Brahman crossbred bull. On the other hand Habib et al. (2003) reported $3.25 \pm 0.042 \mathrm{ml}$ semen per ejaculate in RC breeding bull. These results coincide with the results of the present study. 
Libido, semen quality and fertility of breeding bulls

Table 2: Semen quality of Brahman cross, Holstein Friesian cross and RC breeding bull

\begin{tabular}{|l|r|r|r|c|}
\hline \multicolumn{1}{|c|}{ Semen parameters } & \multicolumn{1}{c|}{$\begin{array}{c}\text { Brahman } \times \\
\text { Local }\end{array}$} & $\begin{array}{c}\text { Holstein- } \\
\text { Friesian } \times \text { Local }\end{array}$ & \multicolumn{1}{c|}{ RC } & $\begin{array}{c}\text { Level of } \\
\text { significance }\end{array}$ \\
\hline Volume (ml) & $4.93 \pm 0.10^{\mathrm{b}}$ & $5.63 \pm 0.16^{\mathrm{a}}$ & $3.86 \pm 0.15^{\mathrm{c}}$ & $* *$ \\
\hline Progressive Motility (\%) & $69.07 \pm 0.66^{\mathrm{b}}$ & $74.73 \pm 0.76^{\mathrm{a}}$ & $63.96 \pm 0.76^{\mathrm{c}}$ & $* *$ \\
\hline $\begin{array}{l}\text { Sperm concentration } \\
\text { (million/ml) }\end{array}$ & $1147.00 \pm 28.75^{\mathrm{a}}$ & $1087.00 \pm 54.41^{\mathrm{a}}$ & $946.40 \pm 6.18^{\mathrm{b}}$ & $*$ \\
\hline Live Spermatozoa (\%) & $76.96 \pm 0.72^{\mathrm{b}}$ & $84.18 \pm 0.62^{\mathrm{a}}$ & $71.64 \pm 0.68^{\mathrm{c}}$ & $* *$ \\
\hline Normal Spermatozoa (\%) & $83.14 \pm 0.72^{\mathrm{a}}$ & $83.18 \pm 1.47^{\mathrm{a}}$ & $74.29 \pm 0.90^{\mathrm{b}}$ & $* *$ \\
\hline$* \mathrm{P}<0.05 * * \mathrm{p}<0.01$ & & &
\end{tabular}

\section{Progressive motility}

The highest progressive motility of fresh semen was found in Holstein cross $(74.73 \pm 0.76)$ followed by Brahman cross (69.07 \pm 0.66$)$ and lowest in RC $(63.96 \pm 0.76)$ breeding bull. This study also revealed that individual motility of fresh semen varied significantly $(p<0.01)$ among the different genetic group of breeding bulls (Table 2). Rahman et al. (2014) reported that the motility of Holstein $\times$ Zebu and RCC were $66.72 \pm 0.99 \%$ and $62.12 \pm 0.97 \%$, respectively and also found the motility was significantly lowest in RCC breeding bull than other breeds which is in line with our present study. Other studies also showed that the percentage of motile sperm was $66.2-76.0 \%$ in Holstein $\times$ Zebu bull (Shaha et al. 2008, Saxena and Tripathi, 1981) whereas Rashid et al. (2015) and Fatematuzzohora et al. (2016) found $67.1 \pm 0.85 \%$ and $69.19 \pm 0.29 \%$ motility in Brahman crossbred bull. These results are in agreement with present study.

\section{Sperm concentration}

Sperm concentration varied significantly among the three genetic group of breeding bulls where the highest sperm concentration was found in Brahman crossbred breeding bull $(1147.00 \pm 28.75$ million $/ \mathrm{ml})$ and lowest in RC $(946.40 \pm 6.18$ million $/ \mathrm{ml})$ though the sperm concentration did not vary significantly between Brahman crossbred and Holstein Frisian crossbred (1087.00 \pm 54.41 million $/ \mathrm{ml}$ ) breeding bull (Table 2). Everett and Bean (1982) found 1000 million/ $/ \mathrm{mm}^{3}$ in Holstein Friesian crossbred bull. Fatematuzzohora et al. (2016) reported $1144.59 \pm 5.73$ million/ml in Brahman crossbred bull and Habib et al. (2003) observed $1247.72 \pm 7.64$ million/ml spermatozoa in RCC bull semen. These results are in line with present study. But the little variation in value might be due to the difference in age, breed, collection frequency, feeding regime (Al-Hakim et al., 1984).

\section{Live spermatozoa percentage}

Analysis of variance shows that genetic group of breeding bull had a significant effect $(p<0.01)$ on live spermatozoa percentage. The highest live sperm percentage was found in Holstein Friesian cross $(84.18 \pm 0.62)$ whereas lowest in RC breeding bull (71.64 \pm 0.68 ) (Table 2 ). Nasrin et al. (2008) also reported that live spermatozoa percentage was consistently lower in RCC than any other bull. The results of the present study also do agree with the previous studies of Hahn et al. (1969) who found $83.5 \%$ live sperm in Holstein bull and Fatematuzzohora et al. (2016) who found $83.55 \pm 0.97 \%$ live spermatozoa in fresh semen of Brahman crossbred breeding bull.

\section{Normal spermatozoa percentage}

In the present study, morphologically highest normal sperm percentage was observed in Holstein Friesian cross breeding bull $(83.18 \pm 1.47 \%)$ and lowest in RC breeding bull $(74.29 \pm 0.90 \%)$. Significant variation $(p<0.01)$ was revealed between Holstein Friesian cross and RC breeding bull but no significant variation was observed in Holstein Friesian and Brahman crossbred breeding bulls (Table 2). Habib et al. (2003) reported that the normal sperm percentage in RCC was $82.24 \pm 0.49 \%$ which is higher than the present study. Nasrin et al. (2008) reported that normal spermatozoa in fresh semen varied significantly with an order of Holstein cross followed by Sindhi and Sahiwal cross and Red Chittagong bulls. Red Chittagong 
bulls had lowest normal sperm percentage compared to other bulls.

\section{Pearson's correlation between libido and semen parameters}

In the present study, it was revealed that libido had a strong and positive correlation with volume (0.133), progressive motility $(0.238$. $\mathrm{p}<0.01)$, sperm concentration $(0.379$, $p<0.001)$, live spermatozoa percentage $(0.087)$ and normal spermatozoa percentage $(0.179$, $p<0.05$ ) (Table 3 ). These results are in agreement with the findings of Singh et al. (2015) who observed a positive correlation of libido score with volume, motility and sperm concentration in Sahiwal bulls. Our result also agreed with the findings of Javed et al. (2000) who reported positive correlation between sperm concentration and mass motility and progressive motility. Wahid and Yunus (1994) reported that there is a positive correlation between libido, semen volume per ejaculates and testicular length.

\section{Fertility}

The fertility of different breeds is shown in Figure 2. From the present study, it was revealed that the fertility rate was significantly $(p<0.05)$ highest in Holstein Friesian crossbred $(63.67 \pm 1.46 \%)$ followed by Brahman crossbred $(58.86 \pm 1.05 \%)$ and lowest in RC (53.42 \pm 0.85$)$ breeding bull (Figure 2).

Rahman et al. (2014) found an average fertility of $67.00 \pm 0.15 \%$ in Holstein $\times$ Zebu cattle which is in line with the present study. The present findings on fertility of RC bulls also agreed with the results of Habib et al. (2012) who found the mean non-return rate to first service of RCC bulls was $58.7 \pm 5.1 \%$. On the other hand, Fatematuzzohora et al. (2016) reported conception rate using Brahman crossbred semen was $56.24 \%$ in Douhakhula region of Mymensingh district. This result coincides with finding of the present study.

Table 3: Correlation coefficient of libido with semen parameters of breeding bulls

\begin{tabular}{|c|c|c|c|c|c|c|}
\hline & Libido & Volume & $\begin{array}{l}\text { Progressive } \\
\text { motility (\%) }\end{array}$ & $\begin{array}{c}\text { Sperm } \\
\text { concentration }\end{array}$ & $\begin{array}{c}\text { Live sperm } \\
(\%)\end{array}$ & $\begin{array}{c}\text { Normal } \\
\text { sperm }(\%)\end{array}$ \\
\hline Libido & 1 & & & & & \\
\hline Volume & 0.133 & 1 & & & & \\
\hline Progressive motility (\%) & $0.238 * *$ & 0.110 & 1 & & & \\
\hline Sperm concentration & $0.379 * * *$ & 0.135 & $0.285^{* *}$ & 1 & & \\
\hline Live sperm (\%) & 0.087 & $0.238^{* *}$ & $0.226 * *$ & 0.130 & 1 & \\
\hline Normal sperm (\%) & $0.179 *$ & $0.258 * *$ & $0.270 * * *$ & $0.176 *$ & $0.254 * *$ & 1 \\
\hline
\end{tabular}

$* \mathrm{p}<0.05, * * \mathrm{p}<0.01, * * * \mathrm{p}<0.001$

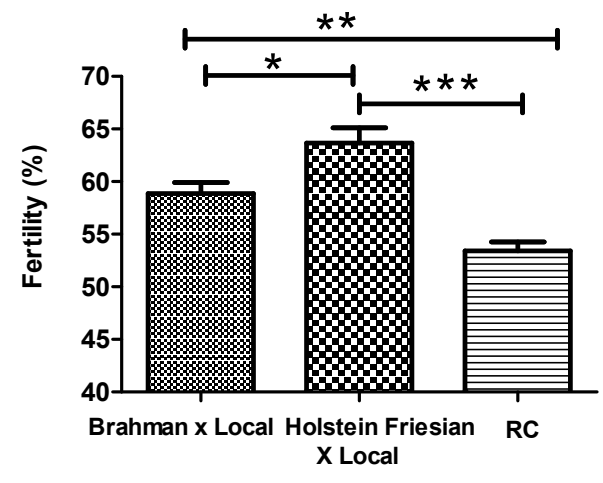

Figure 2: Fertility of Brahman cross, Holstein Friesian cross and RC breeding bulls

\section{Conclusion}

It can be concluded that libido, semen quality and fertility are linked together. Holstein Friesian crossbred breeding bulls have significantly higher libido and better sperm quality than that of Brahman and RCC. Therefore, libido and semen quality should be taken into consideration during breeding bull selection for the higher fertility in AI program.

\section{Acknowledgement}

The authors are grateful to the HEQEP funded project "Innovative Research on Livestock and Poultry (CP-10)", RCC project and Department of Animal Breeding and Genetics, Bangladesh Agricultural University, Mymensingh. 


\section{Libido, semen quality and fertility of breeding bulls}

\section{References}

Adamczyk K, A Makowska, J Jędraszczyk, L Hebda and Z Gil (2013). Effect of behaviour of Holstein-Friesian and Simmental bulls on semen quality. Journal of Central European Agriculture 14:22-34.

Ahmad M, MT Asmat and NR Rehman (2005). Relationship of testicular size and libido to age and season in Sahiwal bulls. Pakistan Veterinary Journal 25:67-70.

Ahmad M, MT Asmat, Najib-ur-Rehman and MZ Khan (2003). Semen characteristics of Sahiwal bulls in relation to age and season. Pakistan Veterinary Journal 23:202-206.

Al-Hakim MK, SBA Ali and BP Singh (1984). Study on semen characteristics of Karadi (Kurdi) bulls. Indian Journal of Animal Health 23:163169.

Andersson M, J Taponena, E Koskinena and $M$ Dahlbomb (2002). Effect of insemination with doses of 2 or 15 million frozen-thawed spermatozoa and semen deposition in dairy cows. Theriogenology 61:1583-1588.

Annual report of Department of Animal Production and Health (DAPH), (2011).

Anzar M, M Ahmad, M Nazir, N Ahmad and IH Shah (1993). Selection of buffalo bulls: Sexual behavior and its relationship to semen production and fertility. Theriogenology 40:1187-1198.

Chenoweth, PJ (1983). Sexual behavior of the bull. A review. Journal of Dairy Science, 66: 173179.

Everett RW and B Bean (1982). Environmental influences on semen output. Journal of Dairy Science 65:1303-1310.

Fateatuzzohora M, MA Haque, MR Islam, MA Hoque and MY Ali (2016). Evaluation of reproductive performance of indigenous cows using Brahma cross-bred bull in a participatory breeding program. Asian-Australasian Journal of Bioscience and Biotechnology 1:173-181.

Habib MA, AKFH Bhuiyan, MSA Bhuiyan and AA Khan (2003). Performance of Red Chittagong cattle in Bangladesh Agricultural University dairy farm. Bangladesh Journal of Animal Science 32:101-108.

Habib MA, AKFH Bhuiyan and MR Amin (2012) Genetic and phenotypic parameter on fertility traits of Red Chittagong Cattle in Bangladesh. The Bangladesh Veterinarian 29:78-89.

Hahn J, RH Foote and GE Seidel (1969). Quality and freezability of semen from growing and aged dairy bulls. Journal of Dairy Science 52:1843-1848.

Herman HA and FW Madden (1963). The Artificia Insemination of dairy and beef cattle.A hand book of laboratory manual, Freeman and Company, San Francisco, USA. pp. 579-610.

Herman HA, JR Michell and GA Doak (1994). The artificial insemination and embryo transfer of dairy and beef cattle: A handbook and laboratory manual, 8th edn. Interested Publishers Company, INC, Danville, Llinois, USA $1994,45-55$.

Javed MT, A Khan and R Kausar (2000). Effect of age and season on some semen parameters of Nili-Ravi buffalo (Bubalusbubalis) bulls. Veterinary Arhcives 70:83-94.

Khan MS, AA Bhatti, SA Bhatti and M Ashiq (2007). Semen production and productive life of Sahiwal bulls: relationship with genetic worth. Pakistan Veterinary Journal 27:20-24.

Kondracki S, M Iwanina, A Wysokinska and $\mathrm{K}$ Gorski (2013). The use of sexual activity measurements to assess ejaculatory performance of boars. Arch. Tierzucht., 56:113.

Leon H, AA Porras and CS Galina (1991). Effect of the Collection Method on Semen Characteristics of Zebu and European Type Cattle in the Tropics. Theriogenology 36:349355

Levis DG and DL Reicks (2005). Assessment of sexual behavior and effect of semen collection pen design and sexual stimulation of boars on behavior and sperm output-A review. Theriogenology 63:630-642.

Mahmood SA, A Ijaz, N Ahmad, H Rehman, H Zaneb and U Farooq (2014). A study on relationships among age, body weight, orchidometry and semen quality parameters in adult Cholistani breeding bulls. Journal of Animal and Plant Science, 24:380-384.

Nasrin S, MR Amin and MK Alam (2008). Evaluation of semen and non-return rate of bulls in Artificial Insemination Centre. Bangladesh Journal of Animal Science 37:1-7.

Ott RS and MA Memon (1980). Breeding soundness examinations of rams and bucks. A review. Theriogenology 13:155-160.

Pound N, MH Javed, C Ruberto, SM Anis and AP Del Valle (2002). Duration of sexual arousal predicts semen parameters for masturbatory ejaculates. Physiology and Behavior 76:685689.

Rahman MA, NS Juyena, JU Ahmed, RN Ferdousy, S Chakma, MZ Rine and AMM Tarif (2014). 
Evaluation of semen for breeding soundness of four different breeds of bull used for artificial insemination. IOSR Journal of Agriculture and Veterinary Science 7:28-34.

Raju MS and AR Rao (1982). Note on the semen characteristics of Cross-bred and purebred bulls. Indian Journal of Animal Science 5:1230-1232.

Rashid MM, MA Hoque, KS Huque and AKFH Bhuiyan (2015). Effect of semen collection frequency and scrotal circumference on semen quality parameters in Brahman $\times$ Local crossbred bulls. Advances in Animal and Veterinary Science 3:677-684.

Rehman H, IA Alhidary, RU Khan, MS Qureshi, U Sadique, H Khan and SH Yaqoob (2016). Relationship of Age, Breed and Libido with Semen Traits of Cattle Bulls. Pakistan Journal of Zoology 48:1793-1798.

Rhen $T$ and $D$ Crews (2002). Variation in reproductive behaviour within a sex: neural systems and endocrine activation. Journal of Neuroendocrinology, 14:517-531.

Saxena VB and SS Tripathi (1981). Seasonal variation in the incidence of sperm morphological abnormalities in dairy bulls regularly used for Artificial insemination. British Veterinary Journal 143:312-317.
Shaha SP, MGS Alam, M Khatun and JU Ahmed (2008). Breeding soundness of stud bulls. The Bangladesh Veterinarian 25:51-61.

Sharma ML, G Mohan and KL Sahni (1991). Characteristics and cryopreservation of semen of Holstein-Friesian bulls under topics. Indian Journal of Animal Science 61:977-979.

Singh S, M Bhakat, TK Mohanty, A Kumar, AK Gupta, AK Chakravarty and P Singh (2015). Sexual behavior and its relationship with semen quality parameters in Sahiwal breeding bulls. Veterinary World 8:745-749.

Soeparna S, W Lina, S Eni, Maidaswar and LT Damayanti (2013). Effect of sprouts (phaseolusaureus) addition in ration on the quality offriesian bull semen. LucrăriştiinţificeSeriaZootehnie 59.

Wahid SA and JM Yunus (1994). Correlation between testicle measurements and libido and semen quality in rams. Asian Journal of Animal Science 7:175-178.

Younis M, HA Samad, N Ahmad and I Ahmad (2003). Effects of age and season on the body weight, scrotal circumference and libido in NiliRavi buffalo bulls maintained at the semen production unit, Qadirabad. Pakistan Veterinary Journal 23:59-65. 